\title{
Biochemical and Pharmacological Characterization of TLBbar, a New Serine Protease with Coagulant Activity from Bothrops barnetti Snake Venom
}

\author{
Magaly Alejandra Brousett-Minaya, Paulo Aparecido Baldasso, \\ Salomón Huancahuire-Vega, and Sérgio Marangoni \\ Department of Biochemistry, Institute of Biology (IB), State University of Campinas (UNICAMP), P.O. Box 6109, \\ 13083-970 Campinas, SP, Brazil \\ Correspondence should be addressed to Salomón Huancahuire-Vega; salomonhv77@yahoo.com.br
}

Received 4 April 2013; Accepted 6 June 2013

Academic Editor: Andreimar Martins Soares

Copyright (C) 2013 Magaly Alejandra Brousett-Minaya et al. This is an open access article distributed under the Creative Commons Attribution License, which permits unrestricted use, distribution, and reproduction in any medium, provided the original work is properly cited.

\begin{abstract}
A thrombin-like enzyme named TLBbar was isolated from Bothrops barnetti snake venom and its biochemical and pharmacological characteristics were determined. TLBbar was purified using size exclusion chromatography and reverse phase HPLC, showing molecular mass of $28750.7 \mathrm{Da}$ determined by mass spectrometry. TLBbar serine protease is basic (pI 7.4) and its structure shows similarity with other serine proteases of snake venom. Optimal proteolytic activity was at $37^{\circ} \mathrm{C}$ and $\mathrm{pH} 8$; this activity was strongly inhibited by PMSF and Leupeptin, however; heparin, and soybean trypsin inhibitor (SBT-I) were ineffective. Kinetic studies on BApNA chromogenic substrate have revealed that TLBbar presents a Michaelis-Menten kinetics, with values of $K_{m}$ and $V_{\max }$ of $0.433 \mathrm{mM}$ and $0.42 \mathrm{nmol} / \mathrm{min}$, respectively. TLBbar showed high clotting activity upon bovine and human plasma, presenting IC of 125 and minimum dose coagulant (MDC) of $2.23 \mu \mathrm{g} / \mu \mathrm{L}$. TLBbar cleavages the A $\alpha$ chain of bovine fibrinogen, with maximal efficiency at $30-40^{\circ} \mathrm{C}$ in the presence of calcium after two hours incubation; this fibronogenolityc activity was inhibited by PMSF and Leupeptin, confirming its classification in the group of serine proteases. In addition, TLBbar is capable of aggregating platelets in the same way that thrombin in concentrations of $2.5 \mu \mathrm{g} / \mu \mathrm{L}$.
\end{abstract}

\section{Introduction}

The snake venom contains a variety of proteins that are studied in the world for biological and pharmacological importance; within their complex composition has proteolytic enzymes which belong to two groups: serine proteases and metalloproteases. Both groups affect the hemostatic system through several mechanisms $[1,2]$.

Over 20 serine proteases families (named S1 to S66) have been identified so far and they are grouped according to their functional and structural similarity. Snake venom serine proteases belong to trypsin S1 family clan SA. To date, a large number of studies, including molecular cloning, have led to the isolation and identification of TLEs mainly from the venom of subfamily Viperinaeand Crotalinae [3-9].

These enzymes have a common catalytic mechanism, which includes high reactivity of the serine residue that has an important role in the formation of the transient acyl-enzyme complex, which is stabilized by the presence of histidine residues and aspartic acid within the active site. The amino acids involved in this mechanism correspond to the catalytic triad (Ser 195, His 57, and Asp 102) that is highly conserved [10]. Serine proteases from snake venom (SVSPs) generally have 12 cysteine residues, 10 of which form five disulfide bonds based on homology to the trypsin, with the other two forming a single disulfide bridge conserved among SVSPs found in length C-terminus [11, 12].

SVSPs exert their effects through the ability to disrupt the blood clotting system of the prey [13]. Studies of these toxins have allowed the elucidation of several pharmacological mechanisms and substantially helped the pharmaceutical industry in search of new drugs $[14,15]$ based on their biological functions, they were classified as fibrinolytic activators, procoagulant, anticoagulant, and platelet aggregation 
activate. The SVSPs procoagulant activate FVII, FX, and prothrombin, and to shorten the clotting times. SVSPs coagulants act directly or indirectly activating prothrombin in the presence of factor V, calcium, and phospholipids. SVSPs anticoagulants act by consumption of functional fibrinogen of the victim and inactivation of the fibrin stabilizing factor (XIII). SVSPs also act on platelet activation, binding to the thrombin receptor to initiate the process of platelet activation and adhesion resulting in the formation of a platelet thrombus [16].

Some of these thrombin-like enzymes from snake venom have been used as anticoagulants in the prevention and treatment of a wide variety of thrombotic conditions, vascular surgery and others. Likewise they are widely used in laboratories and on detection of fibrinogen as a reagent for studies coagulation [15]. Although the list of biochemical and biological actions attributed to thrombin continues to grow, the term gender as applied to the thrombin enzyme poison often implies the ability to induce clotting of fibrinogen. The thrombin-like enzymes have been extensively studied over the past decade for potential therapeutic uses. For example, Ancrod, Batroxobin, and Reptilase are commercially available for the treatment of cardiovascular diseases [17].

SVSPs are found mainly in the venoms of snakes belonging to the Viperidae family with a few occurring in members of the Elapidae, Colubridae, and Hydrophiidae families [12]. Bothrops barnetti of the family Viperidae is an endemic species from Peru that is distributed in the coast between 0 and $1000 \mathrm{~m}$ [18]. The vast majority of snakebites in Peru are inflicted by species of the genus Bothrops [19]. The biology and the biochemistry of a lot of toxins from bothropic venoms have been documented; however, there is scantiness of information about the $B$. barnetti snake venom, recently been reported the proteomic characterization of the venom and some biochemical characteristics of barnettobin, a thrombinlike enzyme from $B$. barnetti $[20,21]$. In this paper we report the purification and the biochemical (proteolytic, kinetic, and structural) and pharmacological characterization (fibrinogenolytic and platelet aggregation) of a new serine protease named TLBbar from B. barnetti snake venom.

\section{Material and Methods}

2.1. Purification of TLBbar. Samples of $400 \mathrm{mg}$ of desiccated crude venom from $B$. barneti were suspended in $8.0 \mathrm{~mL}$ of $0.05 \mathrm{M}$ ammonium bicarbonate $(\mathrm{pH} 8.1)$ and centrifuged at $12.000 \times \mathrm{g}$ for $10 \mathrm{~min}$ at $0^{\circ} \mathrm{C}$. The clear supernatant was applied on a molecular exclusion chromatographic column of Sephadex G-75 $(110 \times 4 \mathrm{~cm})$, previously equilibrated and then eluted with the same buffer. Fractions of $2.5 \mathrm{~mL} /$ tube were collected at a flow rate of eluting with a flow rate of $10 \mathrm{~mL} / \mathrm{h}$ at room temperature. The fraction showing clotting and proteolytic activity upon BApNA substrate (N-benzoylL-arginine-p-nitroanilide) was lyophilized and then applied on C8 column in reverse phase HPLC. Briefly, $5 \mathrm{mg}$ of fraction was dissolved in $250 \mu \mathrm{L}$ of solution A $(0.1 \%$ trifluoroacetic acid-TFA) and centrifuged at $4500 \times \mathrm{g}$ and the supernatant was then applied on the analytical reverse phase HPLC Supelco C8, previously equilibrated with solution A for $15 \mathrm{~min}$. The elution of the protein was conducted using a linear gradient of solution $\mathrm{B}$ ( $66.5 \%$ acetonitrile in solution $\mathrm{A})$ and the chromatographic run was monitored at $280 \mathrm{~nm}$. After elution, the fractions were lyophilized and stored at $-20^{\circ} \mathrm{C}$.

\subsection{Enzyme Assays and Determination of Kinetic Parameters.} Thrombin-like enzyme activity was measured using the BApNA synthetic substrate in 96-well plates. The standard assay mixture contained $40 \mu \mathrm{L}$ of buffer $(10 \mathrm{mM}$ Tris- $\mathrm{HCl}, \mathrm{pH}$ $\left.8.0,10 \mathrm{mM} \mathrm{CaCl}_{2}, 100 \mathrm{mM} \mathrm{NaCl}\right), 200 \mu \mathrm{L}$ of substrate $(1 \mathrm{mM})$, $5 \mu \mathrm{L}$ of water, and $5 \mu \mathrm{L}$ of sample (thrombin-like enzyme) in a final volume of $250 \mu \mathrm{L}$. After the addition of the sample $(5 \mu \mathrm{g})$, the mixture was incubated for up to $10 \mathrm{~min}$ at $37^{\circ} \mathrm{C}$, with the absorbance being read at 10 min intervals. The enzymatic activity, expressed as the initial velocity of the reaction $\left(V_{0}\right)$, under the described conditions was calculated based on the amount of p-nitroaniline released [22]. One unit of enzymatic activity was defined as the amount of enzyme able to release $1 \mu \mathrm{mol}$ of p-nitroanilide/min. Under the same conditions the proteolytic activity was evaluated at different temperature and $\mathrm{pH}$.

The inhibition assays were determined by incubating $5 \mathrm{mM}$ of the inhibitors PMSF (phenylmethyl sulfonyl fluoride), Leupeptin (acetyl-leucyl-leucyl-argial) acid glycolbis (2 aminoetileter)-N,N,N,N-tetraacetic (EGTA), Soybean trypsin inhibitor SBT-I $(5 \mu \mathrm{g} / \mu \mathrm{L})$, Leupeptin, and heparin $(5000 \mathrm{UI} / \mathrm{mL})$ with BApNA $(1 \mathrm{mM})$ in Tris- $\mathrm{HCl}$ buffer, $\mathrm{pH}$ $8.0,(1: 1, \mathrm{v} / \mathrm{v})$ for $30 \mathrm{~min}$ at $37^{\circ} \mathrm{C}$. The remaining proteolytic activity was calculated as the percent activity in relation to the control preparation incubated with no inhibitors, which was considered to be $100 \%$ activity. The Michaelis constant $\left(K_{m}\right)$ and maximum velocity $\left(V_{\max }\right)$ of sample were determined using a Lineweaver-Burk plot. All assays were done three times and the absorbance at $410 \mathrm{~nm}$ was measured using a VERSAMAX 190 microplate reader (Molecular Devices Corporation, Sunnyvale, CA).

2.3. Electrophoresis. Electrophoresis was carried out following the Laemmli method [23]. The degree of purity of fractions was assessed by discontinuous electrophoresis using a final acrylamide concentration of $12 \%$ in the resolving gels (1.0 M Tris- $\mathrm{HCl}, \mathrm{pH} 8.8)$ and $5 \%$ in the stacking gel (0.5 M Tris- $\mathrm{HCl}, \mathrm{pH}$ 6.8). Electrophoretic separation was carried out in a 250 Mighty Small (Hoefer Scientific Instruments) for SDS-PAGE (sodium dodecyl sulfate polyacrylamide gel electrophoresis). Samples were heated at $100^{\circ} \mathrm{C}$ for $5 \mathrm{~min}$ and then ran under both reducing (SDS + $\beta$-mercaptoethanol) and no reducing conditions. The gel was stained with 0.1\% Coomassie Brilliant Blue G-250. Molecular weight markers (Sigma) were phosphorylase b $(97.000 \mathrm{Da})$, bovine serum albumin $(62.000 \mathrm{Da})$, ovalbumin $(45.000 \mathrm{Da})$, glyceraldehyde-3-phosphate dehydrogenase $(30.000 \mathrm{Da})$, carbonic anhydrase $(21.000 \mathrm{Da})$, and $\alpha$ lactalbumin $(14.200 \mathrm{Da})$.

2.4. Amino Acid Analysis. Amino acid analysis was done on a Pico-Tag amino acid analyzer (Waters Corporation, Massachusetts, USA) as described by Heinrikson and Meredith [24]. The purified protein $(30 \mu \mathrm{g})$ was hydrolyzed at $105^{\circ} \mathrm{C}$ for $24 \mathrm{~h}$ in $6 \mathrm{M} \mathrm{HCl}$ acid (Pierce sequencing grade) 
containing $1 \%$ phenol (w/v). The hydrolyzates were reacted with $20 \mu \mathrm{L}$ of derivatization solution (ethanol:triethylamine: water: phenylisothiocyanate, $7: 1: 1: 1, \mathrm{v} / \mathrm{v})$ for $1 \mathrm{~h}$ at room temperature after the phenylthiohydantoin (PTC) amino acids were identified and quantified by HPLC by the comparison of their retention times and peak areas with those of a standard amino acid mixture.

2.5. Determination of the Molecular Mass of the Purified Protein by Mass Spectrometry. An aliquot $(4.5 \mu \mathrm{L})$ of the purified protein was inject by $\mathrm{C} 18(100 \mu \mathrm{m} \times 100 \mathrm{~mm}) \mathrm{RP}$ UPLC (nanoAcquity UPLC, Waters) coupled with nanoelectrospray tandem mass spectrometry on a Q-Tof Ultima API mass spectrometer (MicroMass/Waters) at a flow rate of $600 \mathrm{~nL} / \mathrm{min}$. The gradient was $0-50 \%$ acetonitrile in $0.1 \%$ formic acid over $45 \mathrm{~min}$. The instrument was operated in MS continuum mode and the data acquisition was from $\mathrm{m} / \mathrm{z}$ $100-3.000$ at a scan rate of $1 \mathrm{~s}$ and an interscan delay of $0.1 \mathrm{~s}$. The spectra were accumulated over about 300 scans and the multiple charged data by the mass spectrometer on the $\mathrm{m} / z$ scale were converted to the mass (molecular weight) scale using Maximum Entropy-based software supplied with Masslynx 4.1 software package. The processing parameters were output mass range 6.000-20.000 Da at a "resolution" of $0.1 \mathrm{Da} /$ channel; the simulated isotope pattern model was used with the spectrum blur width parameter set to $0.2 \mathrm{Da}$; the minimum intensity ratios between successive peaks were $20 \%$ (left and right). The deconvoluted spectrum was then smoothed $(2 \times 3$ channels, Savitzky Golay smooth) and the mass centroid values obtained using $80 \%$ of the peak top and a minimum peak width at half height of 4 channels.

2.6. Enzymatic Hydrolysis. The purified protein was hydrolysed with sequencing grade bovine pancreatic trypsin in $0.4 \%$ ammonium bicarbonate, $\mathrm{pH} 8.5$, for $4 \mathrm{~h}$ at $37^{\circ} \mathrm{C}$, at an enzyme: substrate ratio of $1: 100(\mathrm{w} / \mathrm{w})$. The reaction was ceased by lyophilization.

2.7. Analysis of Tryptic Digests. The protein was reduced with $5 \mathrm{mM}$ DTT (Dithiothreitol) for $25 \mathrm{~min}$ at $56^{\circ} \mathrm{C}$ and alkylated with $14 \mathrm{mM}$ Iodoacetamide for $30 \mathrm{~min}$ prior to the addition of trypsin (Promega-Sequence Grade Modified). After the trypsin addition $(20 \mathrm{ng} / \mu \mathrm{L}$ in ambic $0.05 \mathrm{M})$, the sample was incubated for $16 \mathrm{hr}$ at $37^{\circ} \mathrm{C}$. To stop the reaction, formic acid $0.4 \%$ was added and the sample centrifuged at $2500 \times \mathrm{g}$ for $10 \mathrm{~min}$. The pellet was discarded and the supernatant dried. The resulting peptides were separated by $\mathrm{C} 18(100 \mu \mathrm{m} \times$ $100 \mathrm{~mm}$ ) RP-UPLC (nanoAcquity UPLC, Waters) coupled with nano-electrospray tandem mass spectrometry on a QTof Ultima API mass spectrometer (MicroMass/Waters) at a flow rate of $600 \mathrm{~nL} / \mathrm{min}$. The gradient used was $0-90 \%$ acetonitrile in $0.1 \%$ formic acid over $20 \mathrm{~min}$. Before performing a tandem mass spectrum, an ESI/MS mass spectrum (TOF MS mode) was acquired for each HPLC fraction over the mass range of $100-2000 \mathrm{~m} / z$, in order to select the ion of interest, where these ions were subsequently fragmented in the collision cell (TOF MS/MS mode).
Raw data files from LC-MS/MS runs were processed using MassLynx 4.1 SCN662 software package (Waters) and analyzed using the Mascot Distiller v.2.3.2.0, 2009 (Matrix Science, Boston, MA) with SNAKES database (snakes_jun2011 was downloaded from NCBI Taxonomy) release from June 2011, using the following parameters: peptide mass tolerance of $\pm 0.1 \mathrm{Da}$, fragment mass tolerance of $\pm 0.1 \mathrm{Da}$, oxidation as variable modifications in methionine, and trypsin as enzyme.

2.8. Clotting Activity upon Plasma. This activity was assessed using $200 \mu \mathrm{L}$ of citrated human plasma at $37^{\circ} \mathrm{C}$. The activity was characterized for the immediate appearance of fibrin network in the presence of $0.1 \mathrm{M}$ calcium chloride. The minimum dose coagulant (MDC) is defined as the amount of sample able to coagulate plasma $(200 \mu \mathrm{L})$ in 60 seconds [25]. The clotting time was characterized by the first sudden appearance of the fibrin net. This activity was performed with $200 \mu \mathrm{L}$ of human plasma obtained by centrifuging the blood samples $(800 \times \mathrm{g}$ for $10 \mathrm{~min})$. Different concentrations $(1.0,2.5,5.0,10,15$, and $20 \mu \mathrm{g})$ of sample were tested. The coagulation index (CI) was determined according to Cavinato et al. [26], using the formula CI $=t^{-1} \times 1000$, where $t^{-1}=$ reverse time.

2.9. Platelet Aggregation. Platelet aggregation activities were assayed as described by Lee et al. [25]. Briefly, venous blood was collected with informed consent from healthy volunteers who denied taking any medication in the previous 14 days. Collected blood was immediately transferred into polypropylene tubes containing one-tenth of final volume of acid citrate dextrose (ACD-C; citric acid $3 \%$, trisodium citrate $4 \%$, glucose $2 \% ; 1: 9 \mathrm{v} / \mathrm{v})$. Platelet-rich plasma (PRP) was obtained by centrifuging whole blood at $200 \times \mathrm{g}$ for $15 \mathrm{~min}$. PRP was washed in a wash buffer solution $(\mathrm{NaCl} 140 \mathrm{mM}, \mathrm{KCl}$ $5 \mathrm{mM}$, sodium citrate $12 \mathrm{mM}$, glucose $10 \mathrm{mM}$, and saccharide $12 \mathrm{mM} ; \mathrm{pH} 6 ; 5: 7 \mathrm{v} / \mathrm{v}$ ) and centrifuged at $800 \times \mathrm{g}$ for $12 \mathrm{~min}$ at $20^{\circ} \mathrm{C}$. The platelet pellet was gently resuspended in KrebsRinger solution and counts were performed on a Neubauer chamber. The final platelet suspension was adjusted to $1.2 \times$ $10^{8}$ platelets $/ \mathrm{mL}$. The supernatant was discarded. Platelet aggregation was carried out using $400 \mu \mathrm{L}$ of the washed platelet solution in a cuvette and incubated at $37^{\circ} \mathrm{C}$ with constant stirring. The desired concentration of protein was added $3 \mathrm{~min}$ prior to the addition of a platelet aggregation inducer (thrombin). Aggregation was subsequently recorded for 5-10 min with an aggregometer (Chrono-log LumiAggregometer model 560-Ca, Havertown, PA, USA). Assays were performed at $37^{\circ} \mathrm{C}$ with $500 \mu \mathrm{L}$ and aggregation of washed platelets was analyzed after 2 minutes of incubation with different concentrations of the sample $(0.03125,0.0625$, 1.25 , and $2.5 \mu \mathrm{g}$ ) dissolved in $0.15 \mathrm{M} \mathrm{NaCl}$. Control experiments were performed using thrombin as aggregate platelet.

2.10. Fibrinogenolytic Assay. The fibrinogenolytic activity was determined using methods described by Edgar and Prentice [27] with some modifications according to Rodrigues et al. [28] and Vaiyapuri et al. [29]. The experiment 
was performed with bovine fibrinogen solution of $1.5 \mathrm{mg} / \mathrm{mL}$ resuspended in Tris- $\mathrm{HCl} 10 \mathrm{mM}$ pH 7.4 containing $10 \%$ of $0.01 \mathrm{M} \mathrm{CaCl}_{2}$. The sample was incubated in said solution at different concentrations: $0.625,1.25,2.5,5.0,10$, and $20 \mu \mathrm{g}$ at $37^{\circ} \mathrm{C}$ for two hours in a water bath. The reaction was stopped by adding $50 \mu \mathrm{L}$ of denaturing solution (10 M urea, $0.2 \%$ SDS 0,55\%, $50 \mathrm{mM}$ Tris- $\mathrm{HCl}, \beta$-mercaptoethanol, and $0.05 \%$ bromophenol blue) followed by boiling at $100^{\circ} \mathrm{C}$ for 5 minutes. The samples were analyzed by SDS-PAGE $15 \%$. The evaluation of the stability of the proteolytic activity of sample was analyzed in the presence of inhibitors (PMSF, Leupeptin, EDTA, EGTA, SBT-I, and heparin) and different divalent ions $\left(\mathrm{Ca}^{++}, \mathrm{Mg}^{++}, \mathrm{Cd}^{++}, \mathrm{Ba}^{++}, \mathrm{Cu}^{++}\right.$, and $\left.\mathrm{Zn}^{++}\right)$.

2.11. Statistical Analyses. They were reported as mean \pm SEM. The significance of differences among means was assessed by analysis of variance followed by Dunnett's test, when several experimental groups were compared with the control group. Differences were considered statistically significant if $P>$ 0.05 .

\section{Results}

The chromatographic profile of Bothrops barnetti snake venom on Sephadex G-75 revealed four fractions (Bbt IBbt IV) (Figure 1(a)). Each fraction was screened for coagulant and proteolityc activities. Only the fraction Bbt Ia showed coagulant activity on bovine fibrinogen at concentrations ranging from $20 \mu \mathrm{g} / \mathrm{mL}$ and proteolityc activity upon BApNA substrate $(0.166 \mathrm{nmol} / \mathrm{min})$. This fraction was collected for purification on reversed phase HPLC chromatography, resulting in 13 peaks (1-13) (Figure 1(b)). The fraction 11, named TLBbar (thrombin-like B. barnetti), showed high serine protease enzymatic activity upon BApNA substrate $(0.35 \pm 0.017 \mathrm{nmol} / \mathrm{min})$ with properties thrombinlike and was selected for biochemical and pharmacological characterization. The purity of this peak was confirmed by rechromatography on an analytical RP-HPLC Supelco C8 column, showing the presence of only one peak (Figure 1(c)).

SDS-PAGE revealed the presence of an electrophoretic band with $M r$ around 28.5 and $37.5 \mathrm{kDa}$ in the absence and presence of DTT, respectively (Figure 1(b), insert). Mass spectrometry analysis confirmed the homogeneity of the peak TLBbar and determined the molecular mass of $28750.7 \mathrm{Da}$ (Figure 2). Amino acid analysis revealed the following composition: B/31, Z/2, S/18, G/26, H/16, R/112, T/14, A/13, P/23, $\mathrm{Y} / 7, \mathrm{~V} / 15, \mathrm{M} / 5, \mathrm{C} / 8, \mathrm{I} / 16, \mathrm{~L} / 19, \mathrm{~F} / 9, \mathrm{~K} / 15$. Two-dimensional electrophoresis determined isoelectric point of 7.4 (data not shown).

The primary structure was determined by sequence tryptic digested (three peptides via MS/MS mass spectrometry) and deduction of the SwissProt database http://br.expasy .org/.

The study conducted of sequence homology in all three peptides in alignment with other serine proteases from snake venom, as determined and the sequences registered in the database, has demonstrated a high degree of homology with the thrombin-like Calobin, Crotalase, and Flavoxobin isolated from Gloydius ussuriensis, Crotalus adamanteus, and Trimeresurus flavoviridis, respectively (Figure 3). The closed regions represent the consensus sequence between the different thrombin-like serine proteases, indicating both highly conserved and variable regions. The conserved amino acid His at position 57 shows the presence of unchanged catalytic site of serine proteases.

In order to estimate the serine protease activity of TLBbar, DL-BApNA was used and the kinetic parameters were calculated. The proteolityc activity of the purified protein $(0.37 \pm 0.017 \mathrm{moles} / \mathrm{min})$ was higher than that of the whole venom and sephadex fraction $(0.02 \pm 0,0018$ and $0.16 \pm$ $0.01 \mathrm{nmol} / \mathrm{min}$, resp.), showing the efficiency of purification procedure herein described (Figure 4(a)). This activity was inhibited by PMSF, and leupeptin (8.82\% and $4.01 \%$ of residual activity, resp.). Chelating agents such as EDTA and EGTA inhibit the proteolytic activity of TLBbar in approximately $50 \%$ the heparin does not produce significant inhibition (Figure 4(b)). TLBbar showed a Michaelis-Menten kinetic behavior (Figure $4(\mathrm{c})) K_{m}$ and $V_{\max }$ were $0.433 \mathrm{mM}$ and $0.42 \mathrm{nmoles} / \mathrm{min}$, respectively (Figure $4(\mathrm{~d})$ ). The maximum enzyme activity occurred at $37^{\circ} \mathrm{C}$ (Figure $4(\mathrm{e})$ ) and $\mathrm{pH} 8.0$ (Figure 4(f)).

TLBbar was able to induced platelet aggregation on washed platelet preparations (Figure 5). This activity was similar to thrombin (control) at the concentration of $2.5 \mu \mathrm{g} / \mathrm{mL}$ (95\% of aggregation) and was strongly inhibited by preincubation of this protein with PMSF. Lower concentration $(0.625$ and $1.25 \mu \mathrm{g} / \mathrm{mL})$ also induced aggregation reaching $70 \%$ of the activity of thrombin in all cases the aggregation begins after three minutes as compared to control. The TLBbar thrombin-like showed coagulant activity upon human plasma, at different concentrations, was able to induce clot formation with minimum dose coagulant (MDC) of $2.23 \mu \mathrm{g} / \mu \mathrm{L}$ (Figure 6 ) and clotting activity on bovine fibrinogen with coagulant index (CI) of 125 , corresponding to 8 seconds.

The TLBbar thrombin-like was found to degrade the A $\alpha$ chain of fibrinogen but not the $\mathrm{B} \beta$ chain protein fragments appeared as degradation products. The degradation of the A $\alpha$ chain was detectable after 15 minutes of incubation and this chain was degraded completely at two hours (Figure 7(a)). This activity was dose dependent, observing degradation from $1.25 \mu \mathrm{g}$ of TLBbar (Figure 7(b)), with optimal activity between $30^{\circ} \mathrm{C}$ and $40^{\circ} \mathrm{C}$ (Figure $7(\mathrm{c})$ ) and the presence of calcium, magnesium, and barium ions (Figure $7(\mathrm{~d})$ ). Fibrinogenolytic activity was reduced by PMSF and leupeptin (Figure 7(e)).

\section{Discussion}

The new serine protease, TLBbar, was purified from the venom $B$. barnetti by combination of two chromatographic steps: molecular exclusion chromatography Sephadex G-75 followed by reverse phase HPLC (Figures 1(a), and 1(b)). The purification procedure herein described was efficient for the obtainment of the TLBbar toxin, showing high yield with high purity levels (Figure $1(\mathrm{c})$ ) and maintaining their functionality, which could be used in biological studies. 


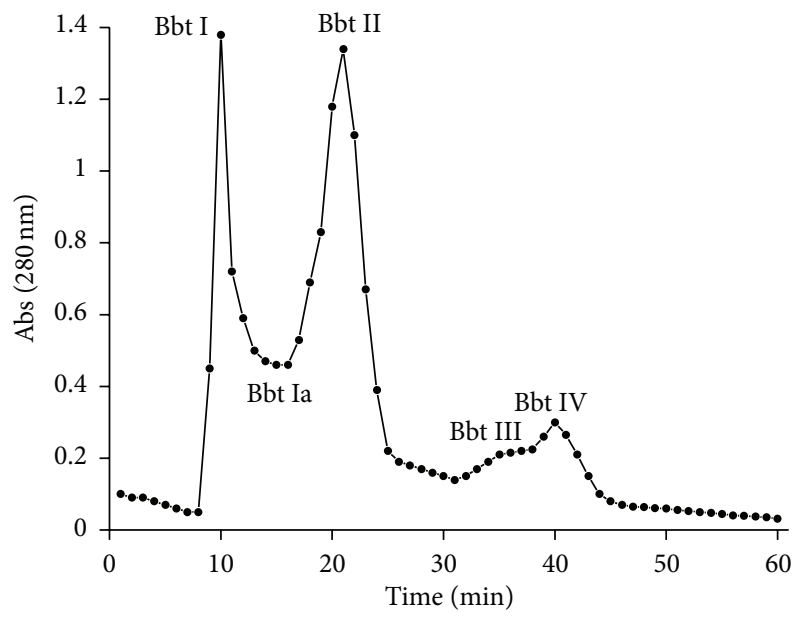

(a)

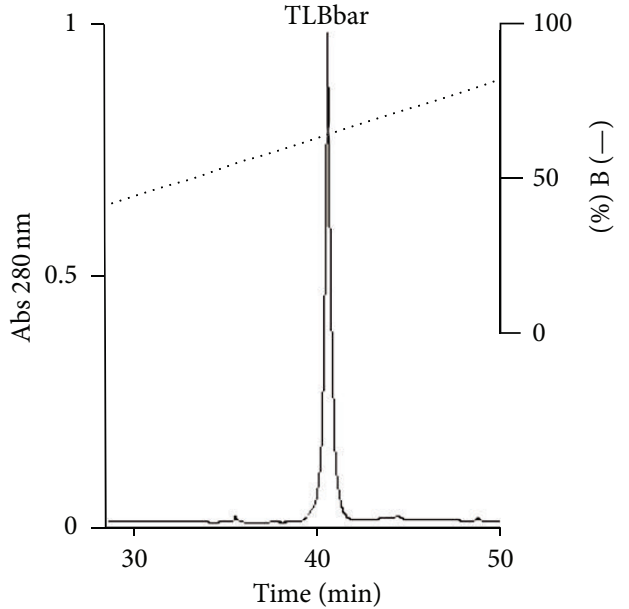

(c)

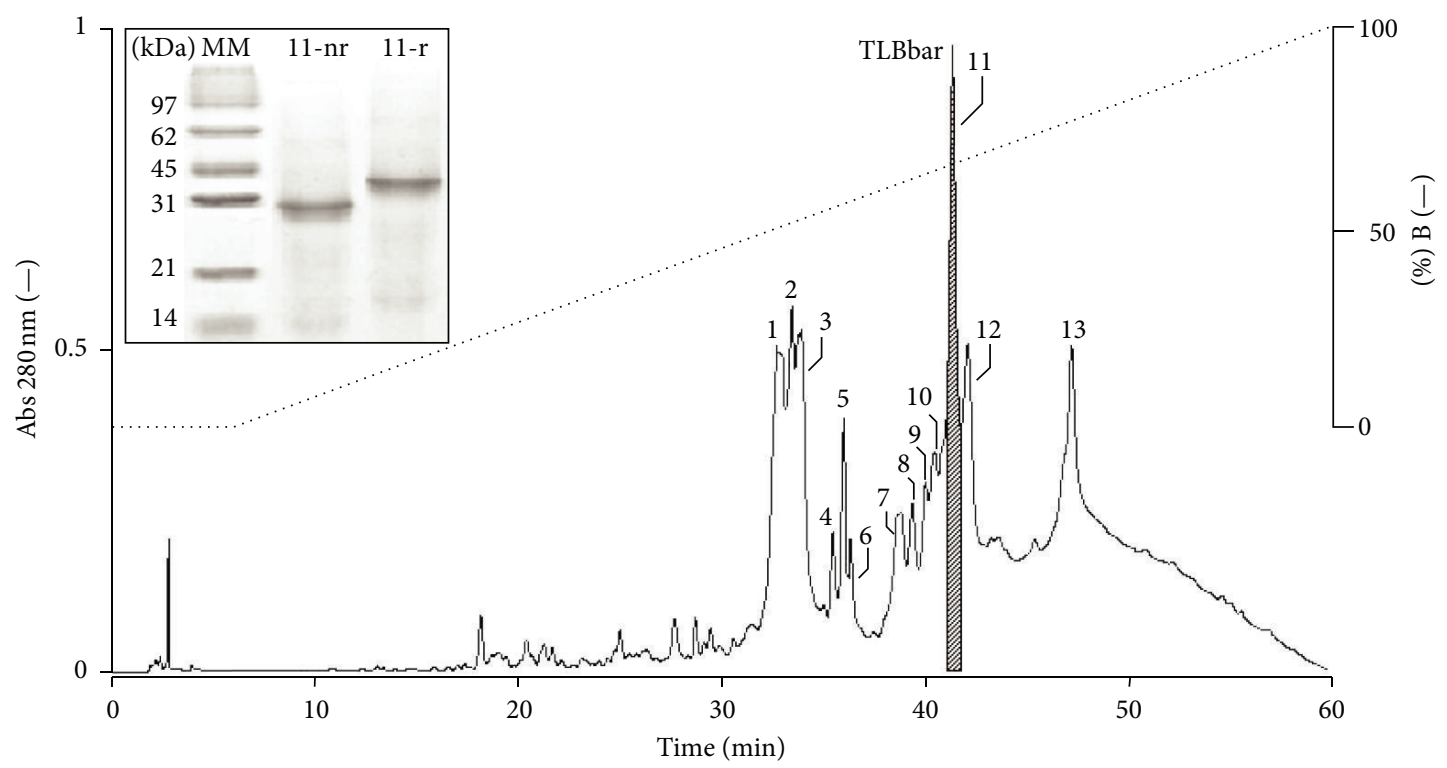

(b)

FIGURE 1: Chromatographic profile of the purification procedure and purity assay of TLBbar. (a) Molecular exclusion chromatography on Sephadex G-75. $(110 \times 4.0 \mathrm{~cm})$ from B. barnetti snake venom. Fraction Bbt Ia $(-)$ showed coagulant and proteolityc activities upon bovine fibrinogen and BApNA substrate, respectively. (b) Elution profile of Bbt Ia fraction by RP-HPLC on an analytical Supelco C8 column. Fraction 11 (TLBbar) showed high serine protease enzymatic activity with properties thrombin-like. Insert: electrophoretic profile in SDS-PAGE: (MM) molecular mass markers, (11-nr) TLBbar not reduced, (11-r) TLBbar reduced with DTT (1 M). (c) Rechromatography on RP-HPLC of TLBbar.

Analysis by SDS-PAGE showed that TLBbar, has one band with $\mathrm{Mr} \sim 28.5 \mathrm{kDa}$, being a protein constituted of a single polypeptide chain (Figure 1(b) insert). TLBm of Bothrops marajoensis [9], Ba III-4 of Bothrops atrox [7], and PABJ of Bothrops jararaca [30] are serine proteases from snake venom that also have structure monomeric.

Figure 2 shows the mass of TLBbar determined by mass spectrometry (ESI positive ionisation). Each peak shown in the spectrum is the protein carrying a different number of charges (protons) [31]. Figure insert shows the deconvolution of the spectrum obtained with the help of software Maximum Entropy. The molecular masses obtained of $28750.7 \mathrm{Da}$ appeared to be similar to those of other snake venom serine proteases as PA-BJ of Bothrops jararaca $30 \mathrm{kDa}$ [30],
Mucrosobin of Trimeresurus mucrosquamatus $28 \mathrm{kDa}$ [32], and RVV-V of Vipera lebetina $24 \mathrm{kDa}$ [33].

Sequence comparison of the peptide containing Nterminal region of TLBbar with several other venom thrombin-like enzymes shows high degree of homology (Figure 3), in particular with Calobin thrombin-like isolated from Agkistrodon caliginosus [34], Crotalase from Crotalus adamanteus [35], and Flavoxobin from Trimeresurus flavoviridis [36]. The other two tryptic peptides have Cys170 and His57 residues highly conserved in the sequence of serine proteases [16]. The whole pattern of Cys residues at the molecular level is forming disulfide bridge and is identical to the mammalian trypsin [3]. Likewise, TLBbar retains the histidine residue at position 57 of the catalytic triad of serine proteases, giving the basic 


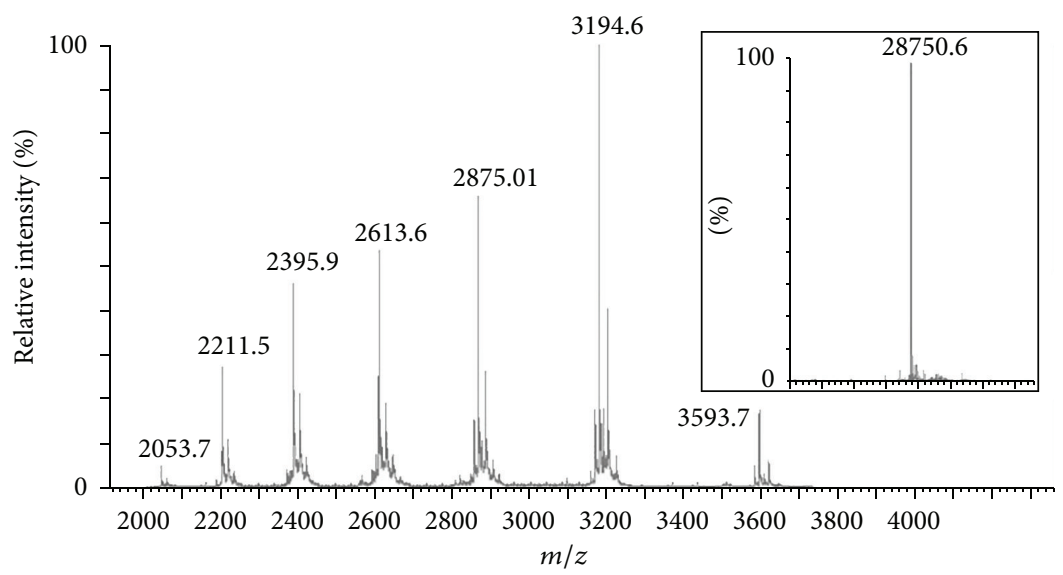

FIGURE 2: Electrospray positive mass spectrum of TLBbar determination by ESI mass spectrometry. The corresponding deconvoluted mass spectrum is shown in the insert.

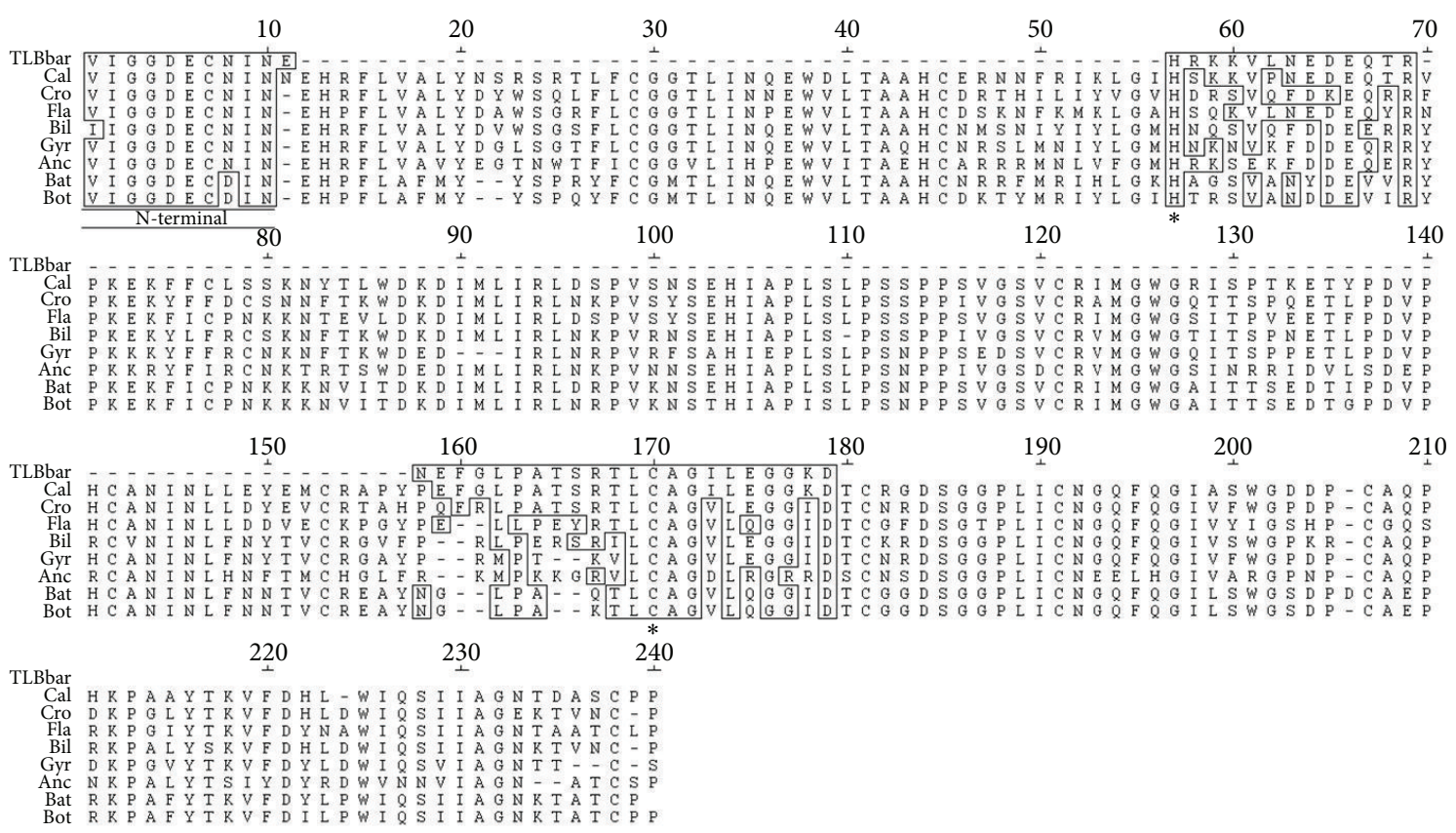

FIGURE 3: Sequence alignment of TLBbar with other SVSPs with thrombin-like activity. Calobin of Agkistrodon caliginosus GI: 1389589 [34]; Crotalase (Cro) of Crotalus adamanteus GI: 384951520 [35]; Flavoxobin (Fla) of Trimeresurus flavoviridis GI: 3915685 [36]; Bilineobin (Bil) of Agkistrodon bilineatus GI: 998903 [50]; Gyroxin (Gyr) of Lachesis muta muta GI: 998903 [51]; Ancrod (Anc) of Calloselasma rhodostoma GI: 247212 [52]; Batroxobin (Bat) of Bothrops atrox GI: 114837 [37], and Bot TL (Bot) of Bothrops jararaca GI: 999161 [53]. The cysteine and histidine residues $(*)$ are highly conserved in all sequences.

polarity in the catalytic triad for hydrolysis of the reaction of the peptide bond [16]. This analysis of homology confirms that TLBbar belongs to the serine proteases family of snake venom.

TLBbar showed $V_{o}$ of 0.35 nmoles/min on BApNA substrate (Figure 4(a)), with Michaelis-Menten kinetic behavior (Figure $4(\mathrm{c})$ ) and $V_{\max }$ and $K_{m}$ of $0.42 \mathrm{nmol} / \mathrm{min}$ and $0.433 \mathrm{mM}$, respectively (Figure $4(\mathrm{~d})$ ); these values are similar to other thrombin-like snake venom, as TLE-1 and TLE-2 isolated from B. atrox $\left(K_{m} 0.33 \mathrm{mM}\right.$ and $0.46 \mathrm{mM}$, resp.) [37] and thrombin-like from Lachesis muta muta $\left(K_{m}\right.$ of $0.075 \mathrm{mM}$ and $V_{\max }$ of $0.36 \mathrm{nmol} / \mathrm{min}$ ) [38]. These results suggested that the catalytic mechanism of this enzyme is probably involved in an active site organization similar to that of trypsin. Proteolytic activity occurs at $37^{\circ} \mathrm{C}$ and $\mathrm{pH} 8$ (Figures $4(\mathrm{e}$ ) and $4(\mathrm{f})$ ), but activity is still in the range of $40^{\circ} \mathrm{C}$ to $45^{\circ} \mathrm{C}$ which indicates the stability of the molecule before the heat due to the presence of disulfide bridges and proper folding to give molecular stability, this stability; is also explained by the nature pecilothermic of snakes, which is considered the adequacy of body temperature against climate change, affecting physiological processes, and development [39].

The proteolytic activity TLBbar was inhibited by Leupeptin and PMSF which inhibit the proteolytic activity of 


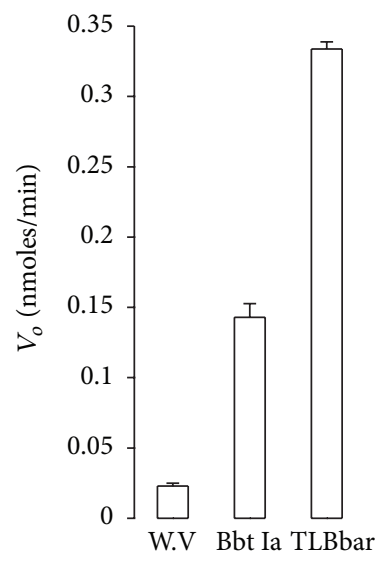

(a)

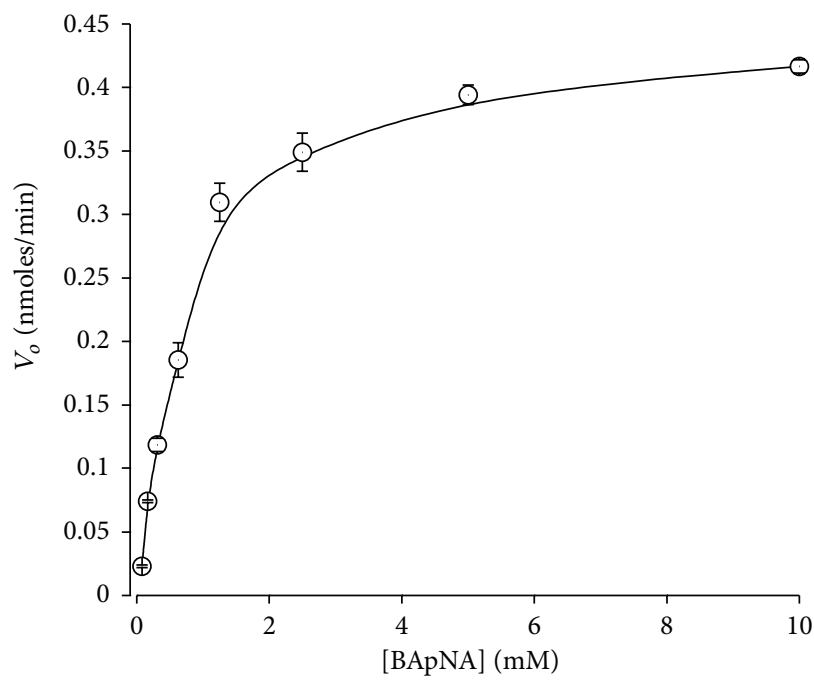

(c)

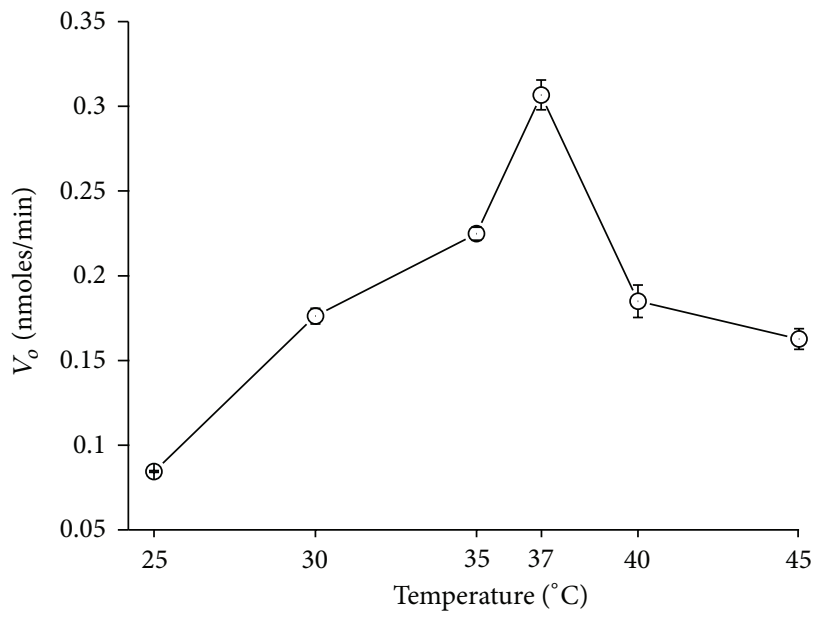

(e)

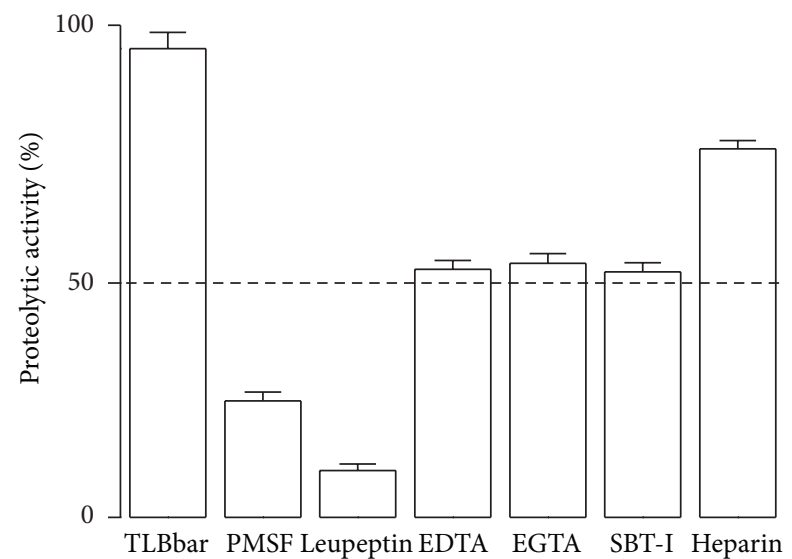

(b)

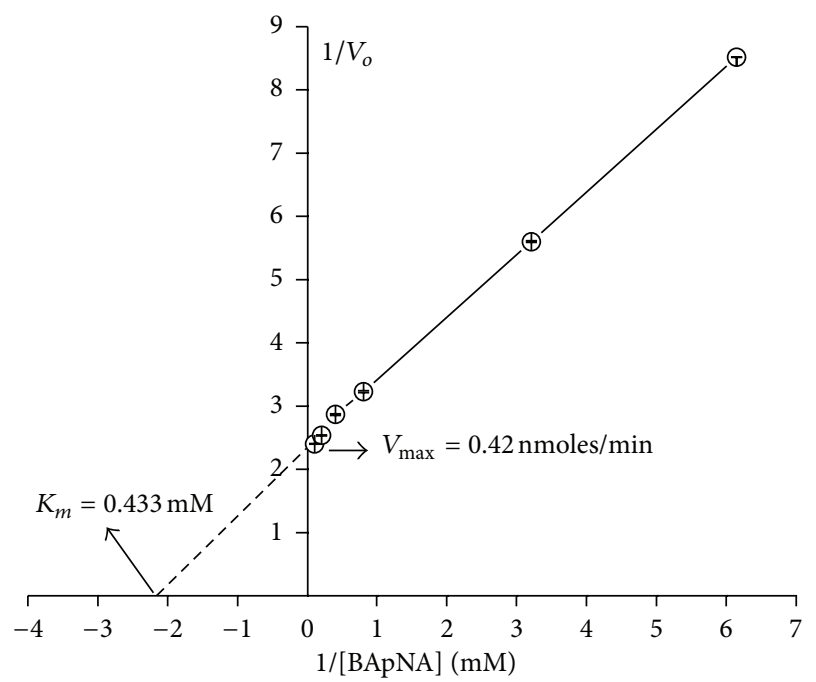

(d)

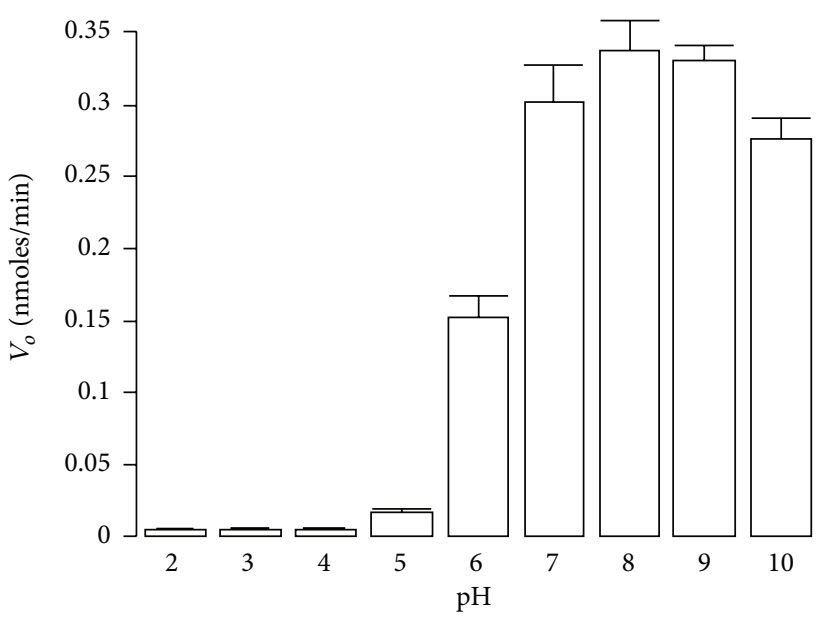

(f)

FIGURE 4: Kinetic properties and inhibition of the thrombin-like enzyme TLBbar from B. barnetti venom upon BApNA substrate. (a) Proteolytic activity of the whole venom B. barnetti (WV) Bbt Ia and TLBbar fractions. (b) Inhibition of the proteolytic activity of TLBbar by PMSF (phenylmethyl sulfonyl fluoride), Leupeptin (acetyl-leucyl-leucyl-argial) EGTA (acid glycol-bis ( 2 aminoetileter)-N,N,N,Ntetracetic), EDTA (Ethylenediamine tetraacetic acid), SBT-I (Soybean trypsin inhibitor), and heparin. (c) Effect of substrate concentration. (d) Lineweaver-Burk (double-reciprocal) plot. (e) Effect of temperature. (f) Effect of pH. The results of all experiments are the mean \pm S.E. of three determinations $(P<0.05)$. 


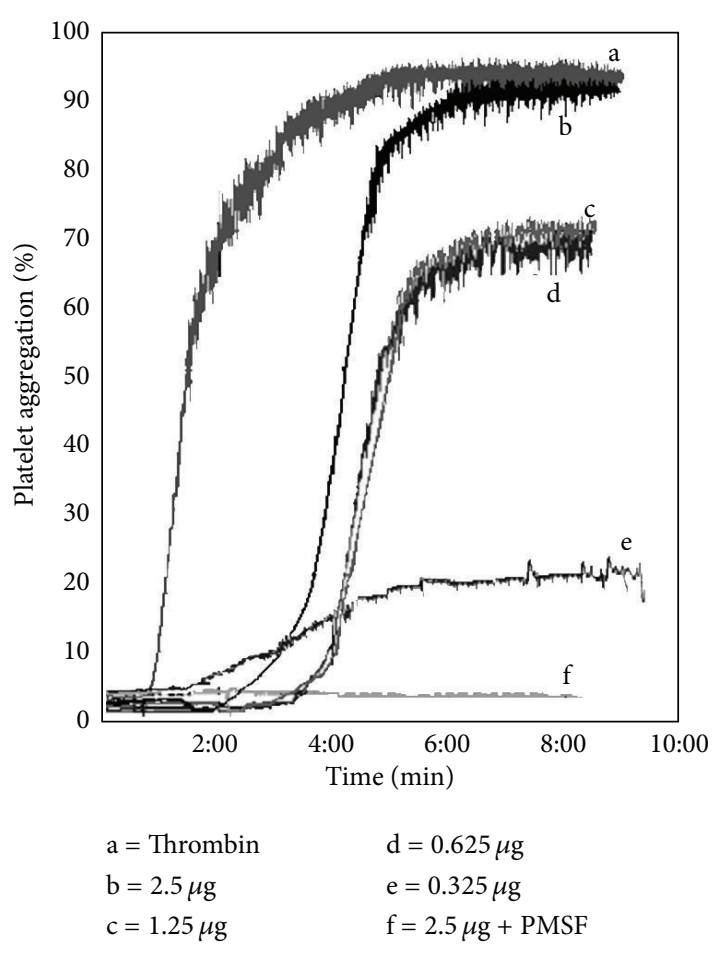

FIGURE 5: Effect of TLBbar on platelets. Different concentrations of TLBbar $(0.03125,0.0625,1.25$, and $2.5 \mu \mathrm{g})$ were evaluated on washed platelets at $37^{\circ} \mathrm{C}$. The control was aggregating thrombin. Significant difference $(P<0.05)$.

SVSPs (Figure 4(b)). Leupeptin is a competitive inhibitor which competes with the substrate for the enzyme active site, being displaced when the substrate is in excess. The PMSF has the ability to bind to the amino acid residue serine of the catalytic site, leading to irreversible binding and inactivating it [40]. TLBbar had residual activity of $4.01 \%$ to $8.82 \%$ for leupeptin and PMSF. These results are compared with other serine proteases that have been inhibited their proteolytic activities with PMSF and Leupeptin, such as halystase from Agkistrodon halys blomhoffii venom [41] and MOO3 from Bothrops moojeni venom [42]. These data confirmed that TLBbar exhibits typical characteristics of snake venom serine protease thrombin-like enzymes.

EDTA and EGTA produce 50\% inhibition; they are chelating agents that sequester the metal ions present in the environment, destabilizing the structure of the molecule and shortening its proteolytic activity. The trypsin inhibitor SBT-I inhibited in some cases at high concentrations [12], in TLBbar, SBT-I, and heparin, had no significant inhibition (Figure 4(b)); they are macromolecules found in the aqueous medium, increase their size as a result of hydration, and probably are unable to get near the catalytic site of serine proteases and prevent their activity. Therefore, the inability of heparin to inhibit the proteolytic activity of TLBbar indicates the existence of structural differences between this enzyme and thrombin, studies crystal structures of serine proteases mammal, both native states as linked to inhibitors should be studied to gain a better understanding this process.

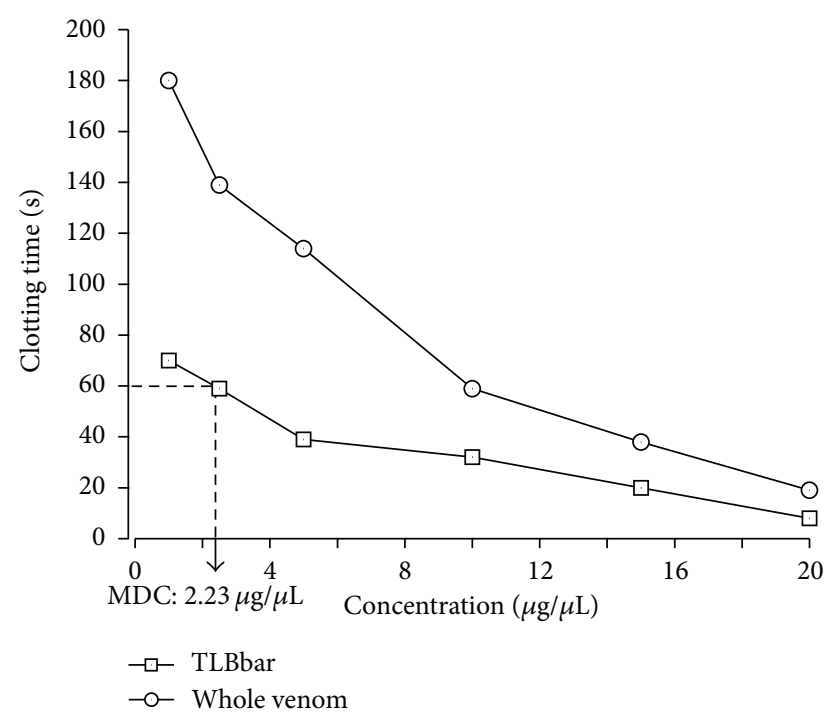

FIgURE 6: Coagulant activity of TLBbar. Minimum dose coagulant (MDC) on TLBbar human plasma at various concentrations $(1,3,5$, $10,15$ and $20 \mu \mathrm{g})$.

The spot appeared in two-dimensional electrophoresis (data not shown) to confirm this basic nature, showing an isoelectric point of 7.4. Acidic and basic serine proteases were isolated from snake venom. The basic serine proteases usually have direct activity on the platelet aggregation; however, the acid proteases exhibit proteolytic activity on protein substrates [12]. TLBbar shows activity on platelet aggregation, confirming the main effect of serine proteases basic.

The results show that TLBbar is capable of aggregating platelets and the concentration of $2.5 \mu \mathrm{g}$ exhibits a behavior similar to the thrombin, reaching $95 \%$ of aggregation (Figure 5). Serine proteases like-thrombin with platelet aggregation activity as Bothrombin from B. jararaca [43], Cerastocitin from Cerastes cerastes [44], and BJ-PA from B. jararaca [30], among others have been discribed. Probably TLBbar activates the thrombin receptor platelet membrane (fibrinogen, factor $\mathrm{V}$, and receptors 1 and 4) coupled to $\mathrm{G}$ protein to initiate intracellular signals that activate the phospholipases, which cleavage membrane phospholipids releasing arachidonic acid, thromboxane $\mathrm{A}_{2}$, calcium, and ADP responsible for the activation of platelets $[29,45]$. The aggregant activity caused by TLBbar was confirmed by inhibition PMSF, causing inhibitory effect as expected. Interestingly TLBbar stimulated aggregation but start time is different compared with thrombin (delayed by approximately 2-3 minutes). The interpretation of the graph has been assessed following the traces of the curve [46] evaluating these studies may suggest that TLBbar activates platelets in a longer time that thrombin which would indicate that the structural variation in membrane surface by releasing agents such as ADP and thromboxane $A_{2}$ is processes that develop more slowly to reach the platelet adhesion.

TLBbar showed clotting activity with IC of 125, corresponding to 8 seconds. The enzyme induces clotting of plasma with a minimum dose coagulant (MDC) of $2.23 \mu \mathrm{g} / \mu \mathrm{L}$ (Figure 6). These values represent high coagulant activity the 


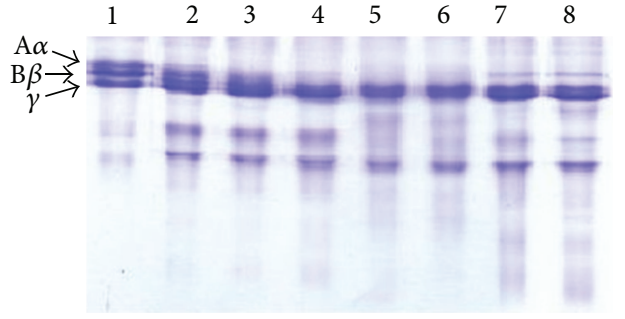

(a)

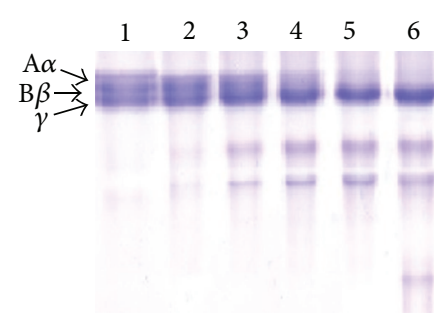

(b)

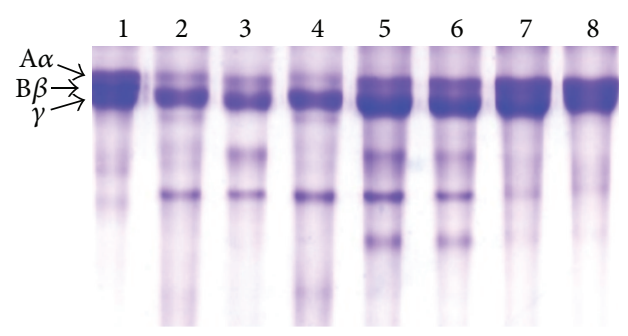

(c)

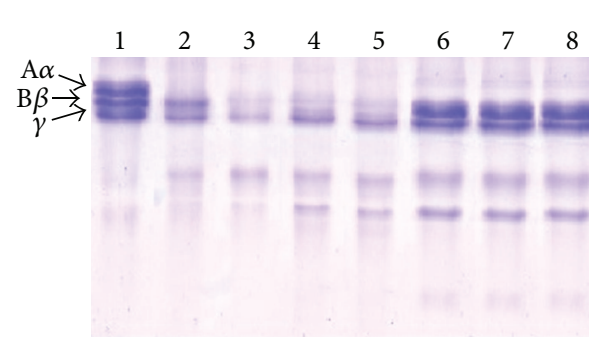

(d)

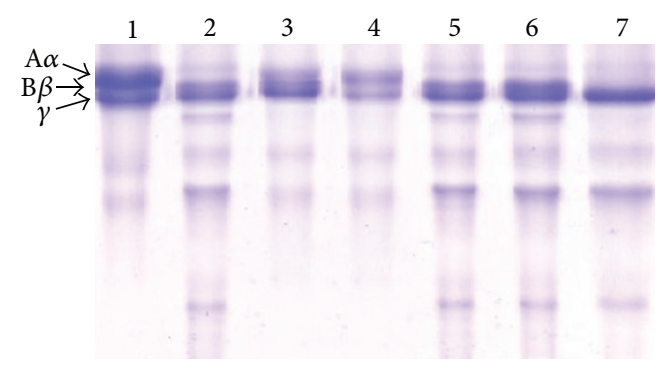

(e)

FIgURE 7: Fibrinogenolytic activity of TLBbar. (a) Time of incubation. (1) Control bovine fibrinogen $1.5 \mathrm{mg} / \mathrm{mL}$; (2) $15 \mathrm{~min}$; (3) $30 \mathrm{~min}$; (4) $60 \mathrm{~min}$; (5) 2 hours; (6) 4 hours; (7) 6 hours; (8) 24 hours. (b) Dose dependent. (1) Control bovine fibrinogen $1.5 \mathrm{mg} / \mathrm{mL}$; (2) $1.25 \mu \mathrm{g}$ TLBbar; (3) $2.5 \mu \mathrm{g}$ TLBbar; (4) $5 \mu \mathrm{g}$ TLBbar; (5) $10 \mu \mathrm{g}$ TLBbar; (6) $20 \mu \mathrm{g}$ TLBbar. (c) Temperature. (1) Control bovine fibrinogen $1.5 \mathrm{mg} / \mathrm{mL}$; (2) $20^{\circ} \mathrm{C}$; (3) $30^{\circ} \mathrm{C}$; (4) $40^{\circ} \mathrm{C}$; (5) $50^{\circ} \mathrm{C}$; (6) $60^{\circ} \mathrm{C}$; (7) $70^{\circ} \mathrm{C}$; (8) $80^{\circ} \mathrm{C}$. (d) Ions. (1) Control of bovine fibrinogen $1.5 \mathrm{mg} / \mathrm{mL}$; (2) TLBbar; (3) TLBbar with $\mathrm{Ca}^{2+}$; (4) TLBbar with $\mathrm{Mg}^{2+}$; (5) TLBbar with $\mathrm{Ba}^{2+}$; (6) TLBbar with $\mathrm{Zn}^{2+}$; (7) TLBbar with $\mathrm{Cu}^{2+}$; (8) TLBbar with Cd ${ }^{2+}$. (e) Inhibition. (1) Control bovine fibrinogen $1.5 \mathrm{mg} / \mathrm{mL}$; (2) TLBbar; (3) Leupeptin; (4) PMSF; (5) EDTA; (6) EGTA; (7) Heparin.

difference of Bothrops asper serine protease which exhibit $\mathrm{MDC}$ of $4.1 \mu \mathrm{g} / \mu \mathrm{L}[47]$. The clot formed is semi rigid, probably TLBbar did not activate the factor XIII and consequently produces a soft clot, different of that produced by thrombin. An exception to this rule is Bitis gabonica, isolated by Pirkle et al. [35] which activates factor XIII [15, 48]. TLBbar coagulant activity leads to the consumption of the content of fibrinogen functional victim or attached without being able to form a stable clot, leading thereby to the blood incoagulability, therefore contributing to hemorrhage. TLBbar confirms its thrombin-like activity acting on fibrinogen to generate fibrin networks.

Snake venom serine proteases (SVSPs) possess three main functions that are responsible for their systemic effects in envenomed victims: fibrinogenolysis reduces the functional fibrinogen content; fibrinolysis dissolves the blood clots, and kininogenolysis generates kinin and bradykinin which alter blood pressure [29]. TLBbar showed fibrinogenolytic activity and degrades fibrinogen $\mathrm{A} \alpha$ chain; its activity is time and dose dependent (Figures 7(a), and 7(b)), with similarity to Bothrombin of B. jararaca [43] and Flavoxobin of Trimeresurus avoviridis [49]. The degradation was observed by cleavage $A \alpha$ chain with $15 \mu \mathrm{g}$ of the enzyme, which starts in 15 minutes, and at two hours there was complete degradation with maximum efficiency. TLBbar is a fibrinogenolytic enzyme that would be classified in the class A (Venombin A). Ratings temperature drop shows that the degradation of A $\alpha$ chain of fibrinogen is greater at temperatures of $30^{\circ} \mathrm{C}$ to $40^{\circ} \mathrm{C}$ (Figure $7(\mathrm{c})$ ), and this activity was increased in the presence of calcium (Figure $7(\mathrm{~d})$ ) confirming that this ion is important and has a role in the coagulation cascade.
Leupeptin and PMSF inhibited the fibrinogenolytic activity of TLBbar (Figure 7(e)) confirming that its catalytic site is responsible for its pharmacological activity and that this activity is the responsibility of TLBbar.

The functions induced for TLBbar are consistent with the effects of systemic poisoning caused by Bothrops snakes such as clotting disorders (fibrinogenolytic activity) and bleeding (fibrinolytic activity) that alter the hemostatic system of the victim.

\section{Conclusion}

We have purified and characterized biochemical and pharmacologically a new serine protease thrombin-like from $B$. barnetti snake venom, named TLBbar. Experimental results have indicated that TLBbar is a new serine protease with fibrigenolytic and coagulant activities and is capable of aggregating platelets. This enzyme showed structural homology with other thrombin-like serine proteases isolated from snake venom. The complete sequence of this protein must be determined. The complete understanding of the sequence, structure, and functional relationships of TLBbar could lead to clinical trials to investigate the potential of this enzyme and can be used to treat hemostatic disorders.

\section{Acknowledgment}

The authors acknowledge the Mass Spectrometry Laboratory at Brazilian Biosciences National laboratory, CNPEMABTLUS, Campinas, Brazil, for their support with the mass spectrometric analyses. 


\section{References}

[1] J. White, "Snake venoms and coagulopathy," Toxicon, vol. 45, no. 8, pp. 951-967, 2005.

[2] Y.-H. Jia, Y. Jin, Q.-M. Lü, D.-S. Li, W.-Y. Wang, and Y.-L. Xiong, "Jerdonase, a novel serine protease with kinin-releasing and fibrinogenolytic activity from Trimeresurus jerdonii venom," Acta Biochimica et Biophysica Sinica, vol. 35, no. 8, pp. 689-694, 2003.

[3] N. Itoh, N. Tanaka, S. Mihashi, and I. Yamashina, "Molecular cloning and sequence analysis of cDNA for batroxobin, a thrombin-like snake venom enzyme," Journal of Biological Chemistry, vol. 262, no. 7, pp. 3132-3135, 1987.

[4] Y. Lin, X. Yu, Q. He et al., "Expression and functional characterization of chitribrisin, a thrombin-like enzyme, in the venom of the Chinese green pit viper (Trimeresurus albolabris)," Protein Expression and Purification, vol. 67, no. 1, pp. 48-52, 2009.

[5] C. Ouyang and F. Y. Yang, "Purification and properties of the thrombin like enzyme from Trimeresurus gramineus venom," Biochimica et Biophysica Acta, vol. 351, no. 2, pp. 354-363, 1974.

[6] E. Oyama and H. Takahashi, "Purification and characterization of a thrombin-like enzyme, elegaxobin, from the venom of Trimeresurus elegans (Sakishima-habu)," Toxicon, vol. 38, no. 8, pp. 1087-1100, 2000.

[7] L. A. Ponce-Soto, V. L. Bonfim, J. C. Novello, R. Navarro Oviedo, A. Yarlequé Chocas, and S. Marangoni, "Isolation and characterization of a serine protease, Ba III-4, from Peruvian Bothrops atrox venom," Protein Journal, vol. 26, no. 6, pp. 387-394, 2007.

[8] S.-S. Tang, J.-H. Zhang, B.-S. Tang et al., "Biochemical and hemostatic mechanism of a novel thrombin-like enzyme," Thrombosis Research, vol. 124, no. 5, pp. 631-639, 2009.

[9] A. Vilca-Quispe, L. A. Ponce-Soto, F. V. Winck, and S. Marangoni, "Isolation and characterization of a new serine protease with thrombin-like activity (TLBm) from the venom of the snake Bothrops marajoensis," Toxicon, vol. 55, no. 4, pp. 745-753, 2010.

[10] R. M. Kini, "Serine proteases affecting blood coagulation and fibrinolysis from snake venoms," Pathophysiology of Haemostasis and Thrombosis, vol. 34, no. 4-5, pp. 200-204, 2006.

[11] M. A. A. Parry, U. Jacob, R. Huber, A. Wisner, C. Bon, and W. Bode, "The crystal structure of the novel snake venom plasminogen activator TSV-PA: a prototype structure for snake venom serine proteinases," Structure, vol. 6, no. 9, pp. 1195-1206, 1998.

[12] S. M. T. Serrano and R. C. Maroun, "Snake venom serine proteinases: sequence homology versus substrate specificity, a paradox to be solved," Toxicon, vol. 45, no. 8, pp. 1115-1132, 2005.

[13] J. Meier and K. Stocker, "Effects of snake venoms on hemostasis," Critical Reviews in Toxicology, vol. 21, no. 3, pp. 171-182, 1991.

[14] S. H. Ferreira, "Angiotensin converting enzyme: history and relevance," Seminars in Perinatology, vol. 24, no. 1, pp. 7-10, 2000.

[15] N. Marsh and V. Williams, "Practical applications of snake venom toxins in haemostasis," Toxicon, vol. 45, no. 8, pp. 11711181, 2005.

[16] T. S. Kang, D. Georgieva, N. Genov et al., "Enzymatic toxins from snake venom: structural characterization and mechanism of catalysis," FEBS Journal, vol. 278, no. 23, pp. 4544-4576, 2011.

[17] T. Nakagaki, P. Lin, and W. Kisiel, "Activation of human factor VII by the prothrombin activator from the venom of Oxyuranus scutellatus (Taipan snake)," Thrombosis Research, vol. 65, no. 1, pp. 105-116, 1992.
[18] N. Carrillo de Espinoza and J. Icochea, "Lista taxonomica preliminar de los reptiles vivientes del Perú," Publicaciones del Museo de Historia Natural de la Universidad Nacional Mayor se San Marcos, vol. 49, pp. 1-27, 1995.

[19] E. Rojas, L. Quesada, V. Arce, B. Lomonte, G. Rojas, and J. M. Gutiérrez, "Neutralization of four Peruvian Bothrops sp. snake venoms by polyvalent antivenoms produced in Perú and Costa Rica: preclinical assessment," Acta Tropica, vol. 93, no. 1, pp. 8595, 2005.

[20] D. E. Vivas-Ruiz, G. A. Sandoval, J. Mendoza et al., "Coagulant thrombin-like enzyme (barnettobin) from Bothrops barnetti venom: molecular sequence analysis of its cDNA and biochemical properties," Biochimie, vol. 95, no. 7, pp. 1476-1486, 2013.

[21] M. Kohlhoff, M. H. Borges, A. Yarleque, C. Cabezas, M. Richardson, and E. F. Sanchez, "Exploring the proteomes of the venoms of the Peruvian pit vipers Bothrops atrox, B. barnetti and B. pictus," Journal of Proteomics, vol. 75, no. 7, pp. 2181-2195, 2012.

[22] B. F. Erlanger, N. Kokowsky, and W. Cohen, "The preparation and properties of two new chromogenic substrates of trypsin," Archives of Biochemistry and Biophysics, vol. 95, no. 2, pp. 271278, 1961.

[23] U. K. Laemmli, "Cleavage of structural proteins during the assembly of the head of bacteriophage T4," Nature, vol. 227, no. 5259, pp. 680-685, 1970.

[24] R. L. Heinrikson and S. C. Meredith, "Amino acid analysis by reverse-phase high-performance liquid chromatography: precolumn derivatization with phenylisothiocyanate," Analytical Biochemistry, vol. 136, no. 1, pp. 65-74, 1984.

[25] W.-H. Lee, X.-Y. Du, Q.-M. Lu, K. J. Clemetson, and Y. Zhang, "Stejnulxin, a novel snake C-type lectin-like protein from Trimeresurus stejnegeri venom is a potent platelet agonist acting specifically via GPVI," Thrombosis and Haemostasis, vol. 90, no. 4, pp. 662-671, 2003.

[26] R. A. Cavinato, H. Remold, and T. L. Kipnis, "Purification and variability in thrombin-like activity of Bothrops atrox venom from different geographic regions," Toxicon, vol. 36, no. 2, pp. 257-267, 1998.

[27] W. Edgar and C. R. M. Prentice, "The proteolytic action of ancrod on human fibrinogen and its polypeptide chains," Thrombosis Research, vol. 2, no. 1, pp. 85-95, 1973.

[28] V. M. Rodrigues, A. M. Soares, R. Guerra-Sá, V. Rodrigues, M. R. M. Fontes, and J. R. Giglio, "Structural and functional characterization of neuwiedase, a nonhemorrhagic fibrin(ogen)olytic metalloprotease from Bothrops neuwiedi snake venom," Archives of Biochemistry and Biophysics, vol. 381, no. 2, pp. 213-224, 2000.

[29] S. Vaiyapuri, R. A. Harrison, A. B. Bicknell, J. M. Gibbins, and G. Hutchinson, "Purification and functional characterisation of rhinocerase, a novel serine protease from the venom of Bitis gabonica rhinoceros," PLoS ONE, vol. 5, no. 3, Article ID e9687, 2010.

[30] S. M. T. Serrano, R. Mentele, C. A. M. Sampaio, and E. Fink, "Purification, characterization, and amino acid sequence of a serine proteinase PA-BJ, with platelet-aggregating activity from the venom of Bothrops jararaca," Biochemistry, vol. 34, no. 21, pp. 7186-7193, 1995.

[31] J. B. Fenn, M. Mann, C. K. Meng, S. F. Wong, and C. M. Whitehouse, "Electrospray ionization for mass spectrometry of large biomolecules," Science, vol. 246, no. 4926, pp. 64-71, 1989.

[32] Y.-W. Guo, T.-Y. Chang, K.-T. Lin, H.-W. Liu, K.-C. Shih, and S.-H. Cheng, "Cloning and functional expression of the 
mucrosobin protein, a $\beta$-fibrinogenase of Trimeresurus mucrosquamatus (Taiwan Habu)," Protein Expression and Purification, vol. 23, no. 3, pp. 483-490, 2001.

[33] E. Siigur, M. Samel, K. Tõnismägi, J. Subbi, T. Reintamm, and J. Siigur, "Isolation, properties and N-terminal amino acid sequence of a factor $\mathrm{V}$ activator from Vipera lebetina (Levantine viper) snake venom," Biochimica et Biophysica Acta, vol. 1429, no. 1, pp. 239-248, 1998.

[34] B.-S. Hahn, K.-Y. Yang, E.-M. Park, I.-M. Chang, and Y.-S. Kim, "Purification and molecular cloning of calobin, a thrombin-like enzyme from Agkistrodon caliginosus (Korean viper)," Journal of Biochemistry, vol. 119, no. 5, pp. 835-843, 1996.

[35] H. Pirkle, I. Theodor, D. Miyada, and G. Simmons, "Thrombinlike enzyme from the venom of Bitis gabonica. Purification, properties, and coagulant actions," Journal of Biological Chemistry, vol. 261, no. 19, pp. 8830-8835, 1986.

[36] M. Deshimaru, T. Ogawa, K.-I. Nakashima et al., "Accelerated evolution of crotalinae snake venom gland serine proteases," FEBS Letters, vol. 397, no. 1, pp. 83-88, 1996.

[37] J. H. Petretski, M. Kanashiro, C. P. Silva, E. W. Alves, and T. L. Kipnis, "Two related thrombin-like enzymes present in Bothrops atrox venom," Brazilian Journal of Medical and Biological Research, vol. 33, no. 11, pp. 1293-1300, 2000.

[38] A. Yarleque, S. Campos, E. Escobar et al., "Isolation and characterization of a fibrinogen-clotting enzyme from venom of the snake, Lachesis muta muta (Peruvian bushmaster)," Toxicon, vol. 27, no. 11, pp. 1189-1197, 1989.

[39] C. R. Peterson, R. A. Gibson, and M. E. Dorcas, "Snake thermal ecology: the causes and consequences of body temperature variation," in Snakes: Ecology and Behavior, R. A. Seigel and J. T. Collins, Eds., pp. 241-314, The Blackburn, Caldwell, NJ, USA, 1993.

[40] C. D. Sant’Ana, F. K. Ticli, L. L. Oliveira et al., "BjussuSP-I: a new thrombin-like enzyme isolated from Bothrops jararacussu snake venom," Comparative Biochemistry and Physiology, vol. 151, no. 3, pp. 443-454, 2008.

[41] T. Matsui, Y. Sakurai, Y. Fujimura et al., "Purification and amino acid sequence of halystase from snake venom of Agkistrodon halys blomhoffi, a serine protease that cleaves specifically fibrinogen and kininogen," European Journal of Biochemistry, vol. 252, no. 3, pp. 569-575, 1998.

[42] F. Oliveira, V. M. Rodrigues, M. H. Borges et al., "Purification and partial characterization of a new proteolytic enzyme from the venom of Bothrops moojeni (Caissaca)," Biochemistry and Molecular Biology International, vol. 47, no. 6, pp. 1069-1077, 1999.

[43] S. Nishida, Y. Fujimura, S. Miura et al., "Purification and characterization of bothrombin, a fibrinogen-clotting serine protease from the venom of Bothrops jararaca," Biochemistry, vol. 33, no. 7, pp. 1843-1849, 1994.

[44] N. Marrakchi, R. B. Zingali, H. Karoui, C. Bon, and M. El Ayeb, "Cerastocytin, a new thrombin-like platelet activator from the venom of the Tunisian viper Cerastes cerastes," Biochimica et Biophysica Acta, vol. 1244, no. 1, pp. 147-156, 1995.

[45] F. Kornalik, "The influence of snake venom enzymes on blood coagulation," Pharmacology and Therapeutics, vol. 29, no. 3, pp. 353-405, 1985.

[46] D. A. Warrell, "Snakebites in Central and South America: epidemiology, clinical features, and clinical management," in The Venomous Reptiles of the Western Hemisphere, J. A. Campbell and W. W. Lamar, Eds., vol. 2, pp. 709-762, Cornell University Press, New York, NY, USA, 2004.
[47] A. V. Pérez, A. Rucavado, L. Sanz, J. J. Calvete, and J. M. Gutiérrez, "Isolation and characterization of a serine proteinase with thrombin-like activity from the venom of the snake Bothrops asper," Brazilian Journal of Medical and Biological Research, vol. 41, no. 1, pp. 12-17, 2008.

[48] K. Stocker, H. Fischer, and J. Meier, "Thrombin-like snake venom proteinases," Toxicon, vol. 20, no. 1, pp. 265-273, 1982.

[49] T.-C. Shieh, S.-I. Kawabata, H. Kihara, M. Ohno, and S. Iwanaga, "Amino acid sequence of a coagulant enzyme, flavoxobin, from Trimeresurus flavoviridis venom," Journal of Biochemistry, vol. 103, no. 4, pp. 596-605, 1988.

[50] T. Nikai, A. Ohara, Y. Komori, J. W. Fox, and H. Sugihara, "Primary structure of a coagulant enzyme, bilineobin, from Agkistrodon bilineatus venom," Archives of Biochemistry and Biophysics, vol. 318, no. 1, pp. 89-96, 1995.

[51] H. C. Castro, D. M. Silva, C. Craik, and R. B. Zingali, "Structural features of a snake venom thrombin-like enzyme: thrombin and trypsin on a single catalytic platform?" Biochimica et Biophysica Acta, vol. 1547, no. 2, pp. 183-195, 2001.

[52] W. Burkhart, G. F. H. Smith, J.-L. Su, I. Parikh, and H. LeVine III, "Amino acid sequence determination of Ancrod, the thrombin-like $\alpha$-fibrinogenase from the venom of Akistrodon rhodostoma," FEBS Letters, vol. 297, no. 3, pp. 297-301, 1992.

[53] T. Kawasaki, Y. Fujimura, Y. Usami et al., "Complete amino acid sequence and identification of the platelet glycoprotein Ibbinding site of Jararaca GPIb-BP, a snake venom protein isolated from Bothrops jararaca," Journal of Biological Chemistry, vol. 271, no. 18, pp. 10635-10639, 1996. 

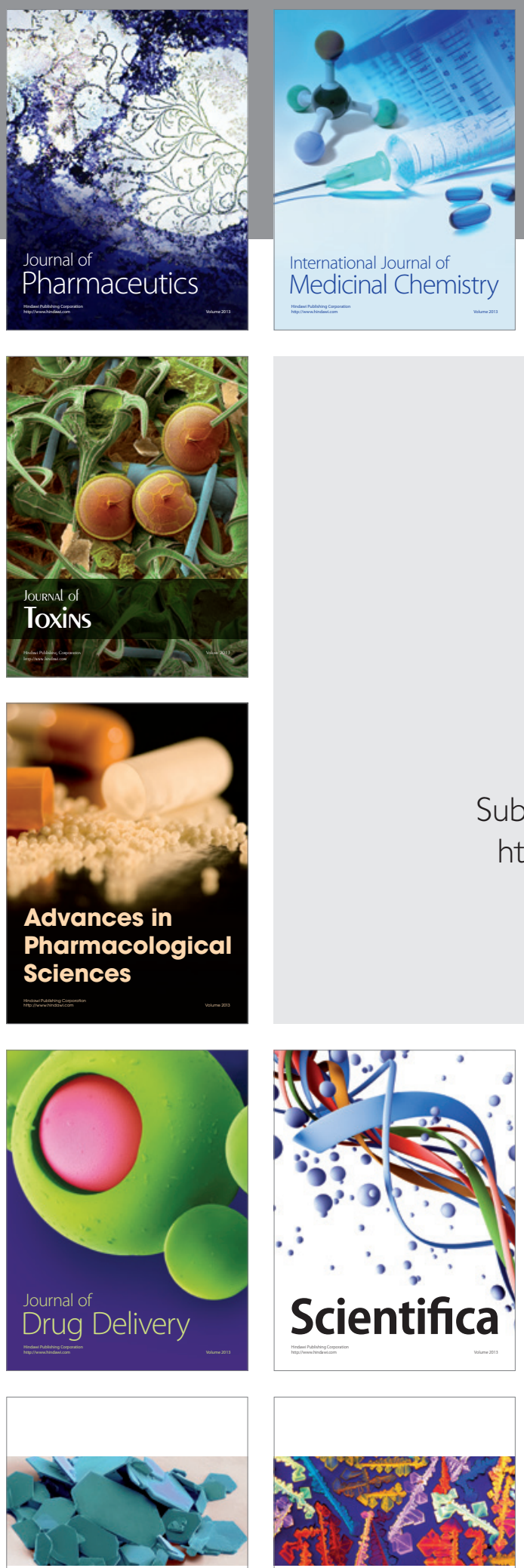

ISRN

Pharmacology

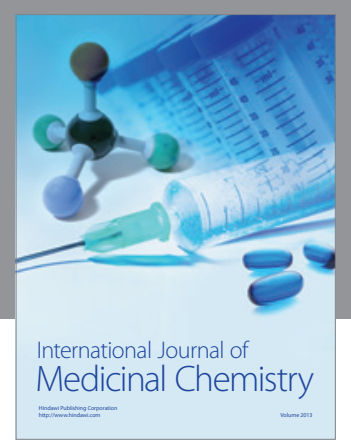

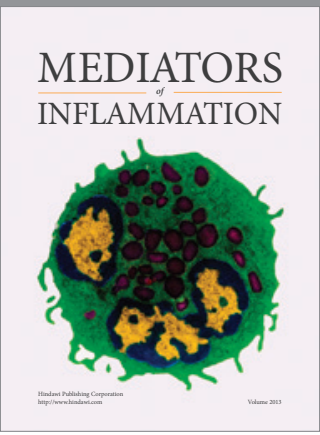
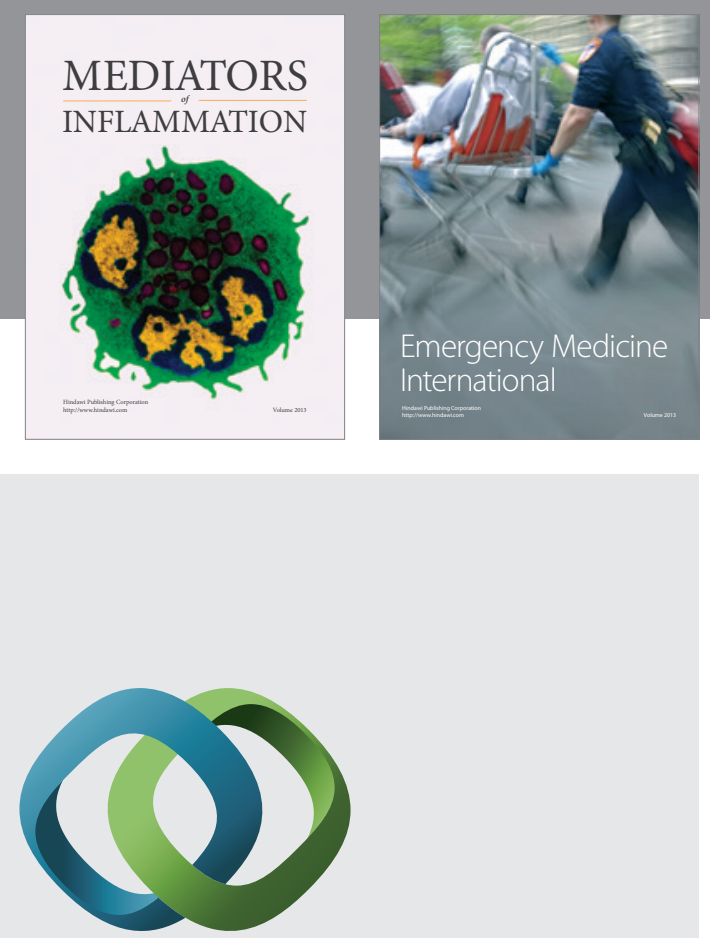

\section{Hindawi}

Submit your manuscripts at http://www.hindawi.com

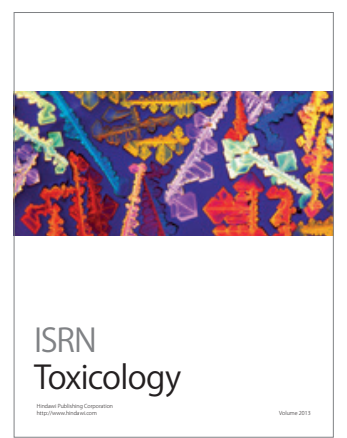

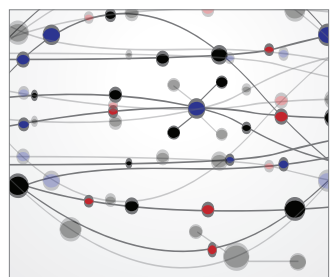

The Scientific World Journal
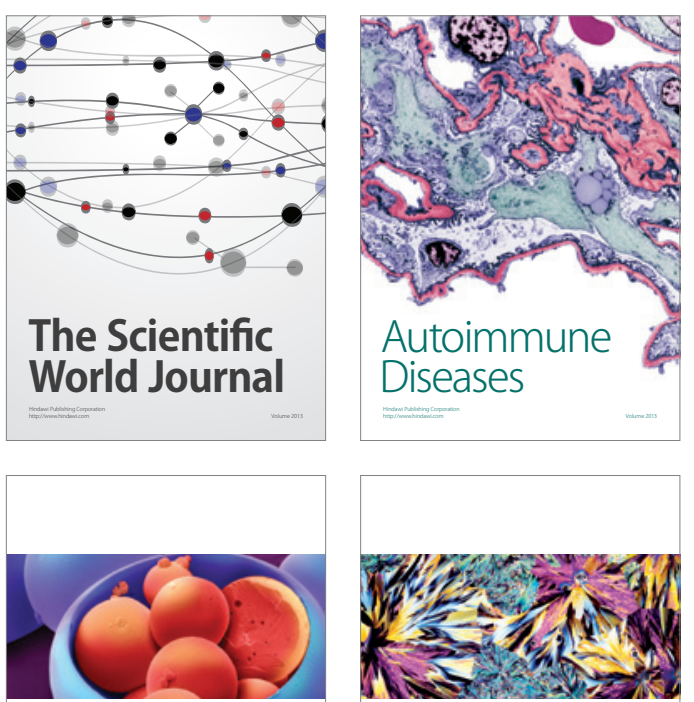

ISRN

Pharmaceutics

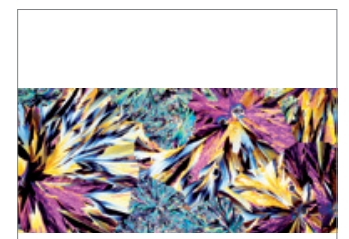

ISRN

Pain
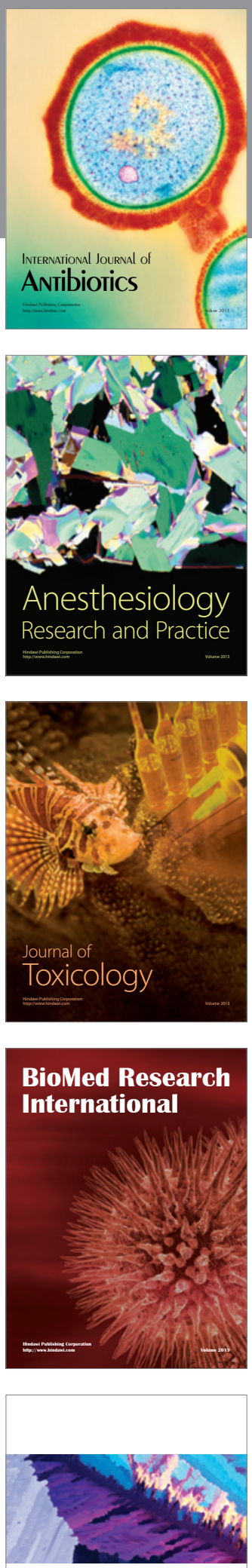

ISRN

Medicinal

Chemistry 